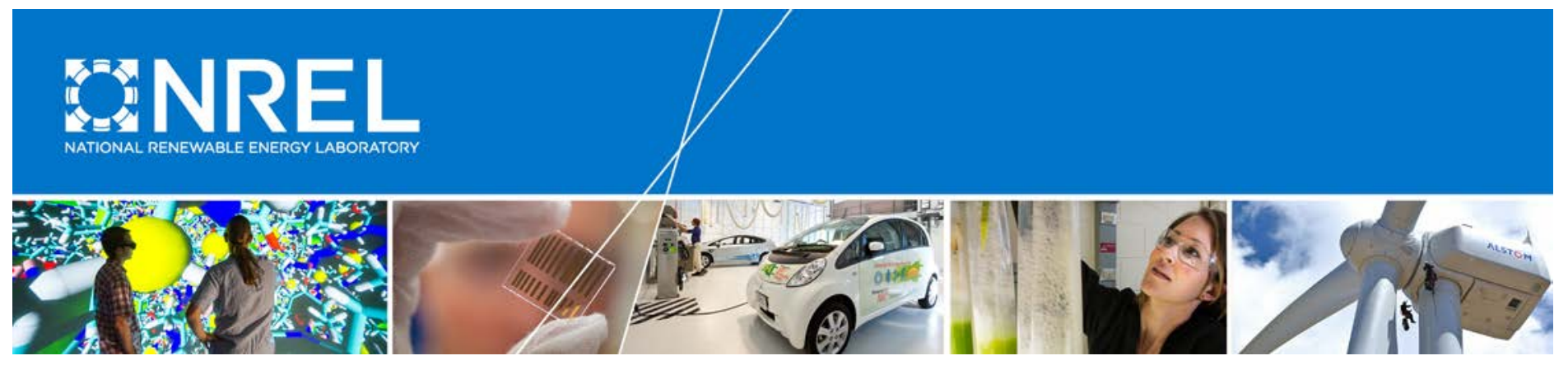

\title{
Quality Assurance Framework Implementation Guide for Isolated Community Power Systems
}

lan Baring-Gould, Sean Esterly, and Kari Burman

National Renewable Energy Laboratory

Chris Greacen Independent Consultant

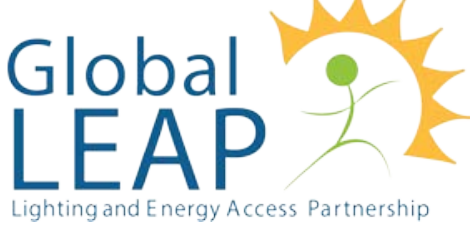

NREL is a national laboratory of the U.S. Department of Energy Office of Energy Efficiency \& Renewable Energy Operated by the Alliance for Sustainable Energy, LLC

This report is available at no cost from the National Renewable Energy Laboratory (NREL) at www.nrel.gov/publications.

Technical Report

NREL/TP-7A40-68634

August 2017

Contract No. DE-AC36-08G028308 


\title{
Quality Assurance Framework Implementation Guide for Isolated Community Power Systems
}

\author{
Ian Baring-Gould, Sean Esterly, and \\ Kari Burman \\ National Renewable Energy Laboratory \\ Chris Greacen \\ Independent Consultant
}

Prepared under Task Nos. DSMG.1000 and WFW8.2000

NREL is a national laboratory of the U.S. Department of Energy Office of Energy Efficiency \& Renewable Energy Operated by the Alliance for Sustainable Energy, LLC

This report is available at no cost from the National Renewable Energy Laboratory (NREL) at www.nrel.gov/publications.

National Renewable Energy Laboratory 15013 Denver West Parkway Golden, CO 80401

303-275-3000 • www.nrel.gov

\section{Technical Report}

NREL/TP-7A40-68634

August 2017

Contract No. DE-AC36-08GO28308 


\section{NOTICE}

This report was prepared as an account of work sponsored by an agency of the United States government. Neither the United States government nor any agency thereof, nor any of their employees, makes any warranty, express or implied, or assumes any legal liability or responsibility for the accuracy, completeness, or usefulness of any information, apparatus, product, or process disclosed, or represents that its use would not infringe privately owned rights. Reference herein to any specific commercial product, process, or service by trade name, trademark, manufacturer, or otherwise does not necessarily constitute or imply its endorsement, recommendation, or favoring by the United States government or any agency thereof. The views and opinions of authors expressed herein do not necessarily state or reflect those of the United States government or any agency thereof.

This report is available at no cost from the National Renewable Energy Laboratory (NREL) at www.nrel.gov/publications.

Available electronically at SciTech Connect http:/www.osti.gov/scitech

Available for a processing fee to U.S. Department of Energy and its contractors, in paper, from:

U.S. Department of Energy

Office of Scientific and Technical Information

P.O. Box 62

Oak Ridge, TN 37831-0062

OSTI http://www.osti.gov

Phone: 865.576.8401

Fax: 865.576.5728

Email: reports@osti.gov

Available for sale to the public, in paper, from:

U.S. Department of Commerce

National Technical Information Service

5301 Shawnee Road

Alexandria, VA 22312

NTIS http://www.ntis.gov

Phone: 800.553 .6847 or 703.605 .6000

Fax: 703.605.6900

Email: orders@ntis.gov 


\section{Acknowledgments}

The authors would like to acknowledge the support of the U.S. Department of Energy (U.S. DOE) International Affairs Office for supporting the development and implementation of the Quality Assurance Framework for mini-grid power systems. This work was funded by the U.S. DOE, the U.S. Department of State, and the U.S. Agency for International Development. This work is also an activity under the Clean Energy Ministerial's Global Lighting and Energy Access Partnership (Global LEAP) initiative, Power Africa's Beyond the Grid initiative, the U.S.-India Promoting Energy Access through Clean Energy (PEACE) initiative, and the Sustainable Energy for All High Impact Opportunity on Clean Energy Mini-Grids.

We would especially like to thank the following individuals who served on a technical review committee for this document and the Quality Assurance Framework project:

- Arne Jacobson, Ph.D: Director, Schatz Energy Research Center at Humboldt State University

- Caroline McGregor: Senior Policy Analyst, U.S. DOE

- Charles Kurnik: Engineer, National Renewable Energy Laboratory

- Dylan Cutler: Engineer, National Renewable Energy Laboratory

- Peter Lilienthal: CEO, HOMER Energy

- Robi Robichaud: Engineer, National Renewable Energy Laboratory

- Rose Mutiso, formerly of the U.S. DOE

- Samuel Booth: Project Leader, National Renewable Energy Laboratory

The challenges of providing power to rural populations are many and multi-faceted. It is hoped that the concepts portrayed in the "Quality Assurance Framework for Mini-Grids" and the "Quality Assurance Framework Implementation Guide for Isolated Community Power Systems" will help to address some of these challenges, an outcome made more likely by the guidance and insight provided by the people named above. 


\section{Table of Contents}

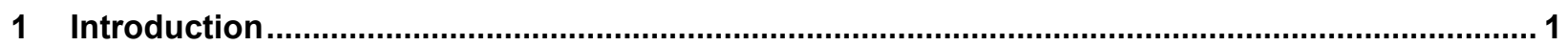

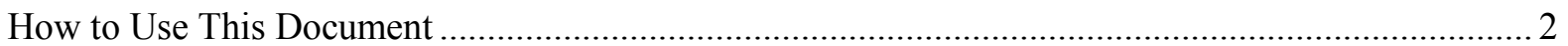

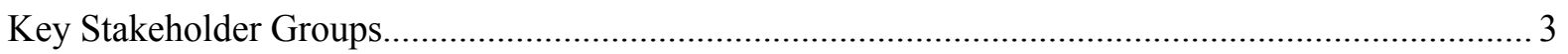

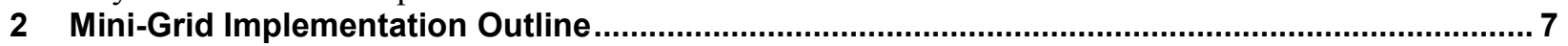

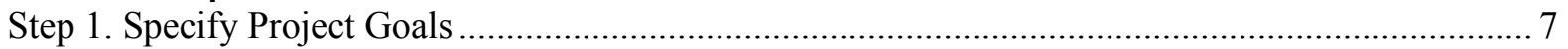

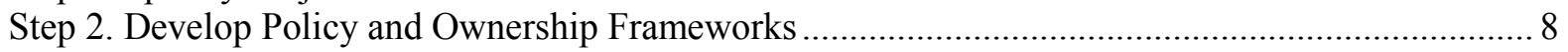

Step 3. Develop Reporting and Measurement Requirements ............................................................ 9

Step 4. Develop Performance, Measurement, and Reporting Plans/Procedures ................................. 11

Step 5. Develop a Project or Program Quality Assurance Verification Process ................................. 13

Step 6. Develop Project Implementation/Requirements Guide/Document for Project Participants .... 14

Step 7. Implement Quality Assurance Verification Process............................................................ 15

Step 8. Implement the Electrification/Mini-Grid Deployment Project/Program................................ 16

Step 9. Collect and Analyze Long-Term System Operational Data ................................................. 16

3 Implementation of the QAF on a Specific Power System …................................................ 19

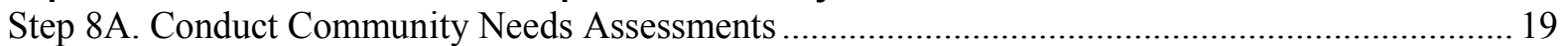

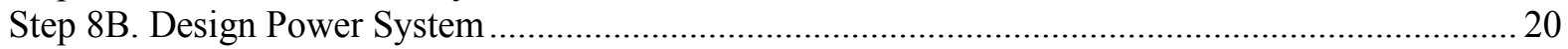

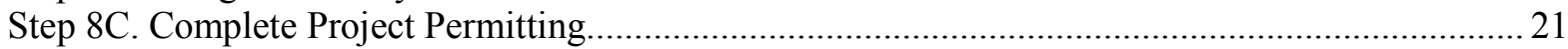

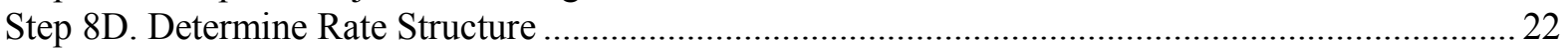

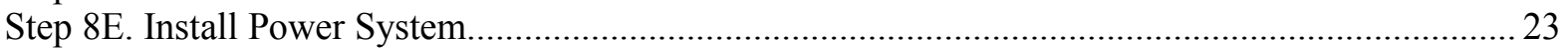

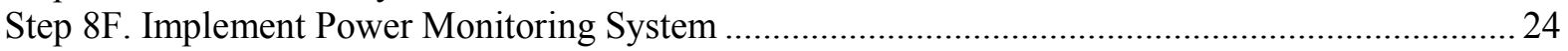

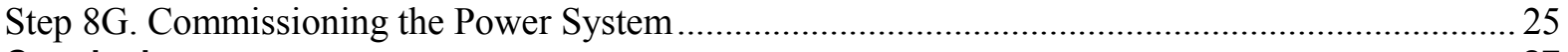

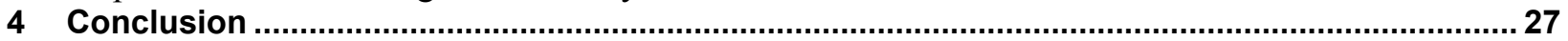




\section{Introduction}

Providing clean and affordable energy services to the more than 1 billion people globally who lack access to electricity is a critical driver for poverty reduction, job creation, and improved health and social outcomes. Distributed energy solutions, such as mini-grids, are critical to providing access to power to a large portion of the unelectrified populations that are located in rural areas where traditional grid extension is not cost effective. The International Energy Agency (IEA) estimates that to achieve universal energy access by 2030 , more than $40 \%$ of total investments will be directed toward mini-grids. ${ }^{1}$

While the fundamental engineering principles of mini-grids are well-established, the details of mini-grid construction and operation vary considerably in practice, and the power quality and reliability of mini-grids can vary widely. Moreover, there is a wide range of development pathways of mini-grid power systems, which greatly expands the risks associated with project development, thus curtailing the willingness of private and public investors to provide the resources that will be needed to increase development. Issues such as the lack of national-level energy development planning, unclear regulatory requirements for off-grid power systems, and sometimes potentially conflicting goals identified by traditional energy suppliers all create additional uncertainty for mini-grid development.

From a technical perspective, the lack of standards further increases project risk, which further discourages private investment. Demand for electrification through mini-grids is also hampered by uncertainty about the quality of service, accuracy of billing, non-cost-reflective tariffs, and safety. These challenges create a major barrier to the scale-up and aggregation needed to lower transaction costs and attract the commercial financial investments that will be necessary for rapid and widespread deployment. An almost complete lack of common language and approach makes it difficult to compare different technology options and business models, and apply lessons learned - all further hindering the scale-up of this market sector.

The Quality Assurance Framework (QAF) for mini-grids was developed in a partnership between the U.S. Department of Energy (DOE) and the National Renewable Energy Laboratory (NREL) with the dual goal of defining a range of service levels that ensure safe, quality, and affordable delivery of basic grid-parity service, and providing an accountability framework that can be used to determine whether an agreed-upon service level is delivered. This will allow the many stakeholders that participate in a mini-grid electrification project, from the investor to the customer, to use common terminology and have a common understanding of roles and responsibilities.

This implementation guide is a companion document to the "Quality Assurance Framework for Mini-Grids" technical report. ${ }^{2}$ This guide includes a detailed overview of the QAF and provides guidance focused on the implementation of the QAF from the perspective of the different

\footnotetext{
${ }^{1}$ International Energy Agency. 2010. "Energy Poverty: How to Make Modern Energy Access Universal." http://www.iea.org/publications/freepublications/publication/weo-2010---special-report---how-to-makemodern-energy-access-universal.html

${ }^{2}$ Ian Baring-Gould, Kari Burman, Mohit Singh, Sean Esterly, Rose Mutiso, and Caroline McGregor, Quality Assurance Framework for Mini-Grids (Golden, CO: National Renewable Energy Laboratory, 2016), http://www.nrel.gov/docs/fy17osti/67374.pdf.
} 
stakeholders that are commonly part of a mini-grid project. To further support the QAF and the implementation guide, technical assistance on applying the QAF to mini-grid projects and programs is available through the Clean Energy Solutions Center's Ask an Expert Program, ${ }^{3}$ and an initial gateway ${ }^{4}$ to information that supports the development of isolated power systems is also available.

\section{How to Use This Document}

This document is intended to be used by one of the many stakeholder groups that take part in the implementation of isolated power systems. Although the QAF could be applied to a single system, it was designed primarily to be used within the context of a larger national or regional rural electrification program in which many individual systems are being installed. The QAF itself is straight forward in concept, and its implementation will be dependent on the perspective and regulatory philosophy of the implementing participants/country.

For the successful long-term implementation of a specific rural electrification program using mini-grid systems, six key stakeholders have been identified that are typically engaged, each with a different set of priorities:

1. Regulatory agency

2. Governmental ministry

3. System developers

4. Mini-utility

5. Investors

6. Customers/consumers.

This implementation guide also identifies an additional category for "other stakeholders." When using this document, it may be educational for program stakeholders to understand the potential roles of other stakeholders, or readers may concentrate on their specific roles in the development process.

Note that in many cases mini-grid projects are developed without participation (or at least without significant participation) from some of the entities identified, largely in the absence of engagement from these organizations. Additionally, each of these organizations can work, and in some cases have worked, to impede the development of mini-grid projects by exercising their roles in a way to slow or stop development as compared to improving it. With this in mind, we must accept that the development of mini-grid power systems in many regions have occurred precisely because some of the specified stakeholders have not been involved in the process. This obviously isn't an ideal situation, as the lack of policy or regulatory clarity, consumer support, access to capital, and sustainable technology options will limit the longer-term viability of minigrid development to support rural electrification needs.

\footnotetext{
${ }^{3}$ https://cleanenergysolutions.org/expert.

4 https://cleanenergysolutions.org/qaf.
} 
This document is intended to provide guidance to organizations that are intent on expanding the role mini-grid power systems could play in providing energy services to isolated communities and rural populations. With this in mind, this document highlights and provides guidance on the potential role each of these organizations has in expanding energy development within specific communities or regions. It is therefore assumed that these organizations will act collaboratively, with a development-focused agenda to support community electrification.

This document is broken into two distinct sections. The first focuses on the administrative processes in the development and operation of community-based mini-grid programs, while the second focuses on the process around the installation of the mini-grid project itself. At the highest level, the steps in each of these processes are described with the specific focus of the role of the different stakeholder groups highlighted. The icons described below and used throughout the document allow someone who represents a specific stakeholder to understand their role in each step of the development process. Although this document can be read from top to bottom, it can also be used to refer to specific individual sections that represent different steps in the development, operation, and installation process.

\section{Key Stakeholder Groups}

Understanding that every project will be different and that many stakeholders will be involved in the development of any large project, the following general key stakeholder roles are defined:

Regulatory authority or regulator: Independent entity primarily focused on the provision of safe, reliable, affordable power to identified communities, wielding licensing and tariff approval as primary tools. In rare instances, the regulator may be the organization that will implement rural energy projects on a national scale but is more likely to only engage once the projects are operating or in the development of project specifications. In the full implementation of a national scale rural electrification program using isolated power systems, the regulator will be required to verify the operation and performance of power systems. This verification process would likely entail field work performed by regulatory staff or designated subcontractors and may require specialized training. In the following text, the roles of regulatory organizations are identified with the dark red icon displayed on the left.

Government energy ministry: This organization is generally responsible for program planning and the implementation of policies to meet government electricity objectives (energy access, renewable energy, etc.). The Ministry typically leads the rural electrification programs and projects in providing general oversight and convening appropriate stakeholders. The Ministry may support the design and implementation of the specific power systems or oversee rural energy development projects. In some cases, a national utility, either independent or directly under an Energy Ministry, will perform this role, especially if they are not directly involved in off-grid electrification activities. In the following text, the roles of ministry organizations are identified with the blue icon displayed on the left.

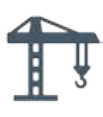

Power system developers: Responsible for the design and construction of the power system. Developers may be combined with the utility that is providing the power over the long term. Developers may also conduct energy needs assessments of communities or other energy-related services. In some cases, developers may also be equipment 
suppliers, but not necessarily. In the following text, the roles of power system developers are identified with the gray icon displayed on the left.

Mini-utility: Responsible for the long-term operation and maintenance of the power system, the mini-utility may also take part in the design and construction of the power system. They are primarily concerned with providing a quality product while returning a sustainable profit from the enterprise. The specific organizational context of a mini-utility is not defined in this document and could include private entities, a cooperative, a municipal service, or another organizational entity. In the following text, the roles of mini-utilities are identified with the orange icon displayed on the left.

Investors: Parties providing funding for the project(s)/programs, either in terms of grants, loans, or equity investments. Investors are concerned with the long-term (financial) sustainability of the project, including the provision of electrical services and, if applicable, a return to the investors who provided the funding. Funding may come from private investors, a government funding organization, an international lending institution, a commercial bank, or a donor organization. Depending on the organization, investors may also incorporate additional nonmonetary considerations, such as the use of specific technologies or specify outcomes such as poverty alleviation (in the case of multinational development organizations). In the following text, the role of the investment community is identified with the green icon displayed on the left.

Customers/consumers: People, organizations, and companies receiving energy services from a power system or through an electrification program. Consumers are concerned with the long-term provision of safe and usable power from the end-user perspective, providing a value commensurate with the price being paid. In the following text, the role of the customer is identified with the light blue icon displayed on the left.

Other: In larger rural electrification implementation programs, additional organizations, such as consumer-focused, nongovernmental organizations (NGOs) or support agencies, may take an active role through the development, implementation, and sustainability phases of the programs or individual projects. The exact nature of the interaction or engagement of these groups will be determined as the program is developed, but they are typically quite important in ensuring long-term project sustainability. In the following text, the role of the additional stakeholders is identified with the light green "other" icon displayed on the left.

These general stakeholder groups are provided based on the described roles they fill. In many cases, multiple organizations may fit into a single category, for example a finance ministry, domestic or international banks, and multilateral donor organizations may all take part in a single electrification program as investors. Additionally, single organizations may provide services that cover multiple stakeholder groups, such as a single company that may both develop and operate a mini-grid power system. It will likely be noted that this document is written with a bias that assumes a governmental organization is leading program/project development, as that is the case in many efforts to provide energy services to isolated or rural populations.

A large-scale process such as the QAF is assumed to be implemented primarily in large-scale rural electrification programs, although this is not generally intentional and the principles behind the QAF could also be applied to individual projects or by private organizations implementing 
projects largely outside of governmental oversight. However, in most cases these large-scale projects will be implemented by national governments and/or large development banks, which in many ways have similar frames of reference.

Understanding that every project and every organization is different, Table 1 provides a visual summary of the program development steps and which organizations are likely to be involved in implementing the QAF as part of a large, mini-grid-focused development program.

Table 1. Program Development Steps Mapped to Likely QAF Implementers

\begin{tabular}{|c|c|c|c|c|c|c|c|}
\hline $\begin{array}{c}\text { Program } \\
\text { Development Step }\end{array}$ & Regulator & Ministry & Developers & Mini-utility & Investors & Customers & OTHER \\
\hline $\begin{array}{l}\text { 1-Specify project } \\
\text { goals (page } 7 \text { ) }\end{array}$ & • & • & & & • & & $\bullet$ \\
\hline $\begin{array}{l}\text { 2-Develop policy } \\
\text { and ownership } \\
\text { frameworks (page } \\
8 \text { ) }\end{array}$ & $\bullet$ & $\bullet$ & & & & & $\bullet$ \\
\hline $\begin{array}{l}\text { 3-Develop reporting } \\
\text { and measurement } \\
\text { requirements (page } \\
\text { 9) }\end{array}$ & $\bullet$ & $\bullet$ & $\bullet$ & $\bullet$ & $\bullet$ & & $\bullet$ \\
\hline $\begin{array}{l}\text { 4-Develop } \\
\text { performance, } \\
\text { measurement, and } \\
\text { reporting } \\
\text { plans/procedures } \\
\text { (page 11) }\end{array}$ & $\bullet$ & $\bullet$ & & $\bullet$ & $\bullet$ & & $\bullet$ \\
\hline $\begin{array}{l}\text { 5-Develop a project } \\
\text { or program quality } \\
\text { assurance } \\
\text { verification process } \\
\text { (page 13) }\end{array}$ & $\bullet$ & $\bullet$ & & $\bullet$ & $\bullet$ & & \\
\hline $\begin{array}{l}\text { 6-Develop project } \\
\text { documentation } \\
\text { (page 14) }\end{array}$ & $\bullet$ & $\bullet$ & & & $\bullet$ & & $\bullet$ \\
\hline $\begin{array}{l}\text { 7-Implement quality } \\
\text { assurance } \\
\text { verification process } \\
\text { (page 15) }\end{array}$ & $\bullet$ & $\bullet$ & & & $\bullet$ & & \\
\hline $\begin{array}{l}\text { 8-Implement the } \\
\text { electrification/mini- } \\
\text { grid deployment } \\
\text { project (page } 16 \text { ) }\end{array}$ & $\bullet$ & $\bullet$ & $\bullet$ & $\bullet$ & $\bullet$ & $\bullet$ & $\bullet$ \\
\hline
\end{tabular}




\begin{tabular}{|c|c|c|c|c|c|c|c|}
\hline $\begin{array}{c}\text { Program } \\
\text { Development Step }\end{array}$ & Regulator & Ministry & Developers & Mini-utility & Investors & Customers & OTHER \\
\hline $\begin{array}{l}\text { A-Conduct } \\
\text { community } \\
\text { needs } \\
\text { assessments } \\
\text { (page 19) }\end{array}$ & & • & • & & • & • & - \\
\hline $\begin{array}{l}\text { B-Design power } \\
\text { system (page } \\
20 \text { ) }\end{array}$ & & • & $\bullet$ & • & & & \\
\hline $\begin{array}{l}\text { C-Complete } \\
\text { project } \\
\text { permitting (page } \\
21 \text { ) }\end{array}$ & $\bullet$ & • & $\bullet$ & & & • & • \\
\hline $\begin{array}{l}\text { D-Determine } \\
\text { rate structure } \\
\text { (page 22) }\end{array}$ & • & • & & • & • & • & - \\
\hline $\begin{array}{l}\text { E-Install power } \\
\text { system (page } \\
23 \text { ) }\end{array}$ & • & & • & & & & \\
\hline $\begin{array}{l}\text { F-Implement } \\
\text { power } \\
\text { monitoring } \\
\text { system (page } \\
24 \text { ) }\end{array}$ & • & $\bullet$ & • & • & • & & \\
\hline $\begin{array}{l}\text { G- } \\
\text { Commissioning } \\
\text { the power } \\
\text { system (page } \\
\text { 25) }\end{array}$ & $\bullet$ & • & • & - & • & & \\
\hline $\begin{array}{l}\text { 9-Collect and } \\
\text { analyze long-term } \\
\text { system operational } \\
\text { data (page 16) }\end{array}$ & • & & & - & • & • & - \\
\hline
\end{tabular}




\section{Mini-Grid Implementation Outline}

This section provides a high-level, step-by-step overview of the processes used in the implementation of either a single mini-grid project or a rural electrification program that might include the electrification of multiple communities, each with individual mini-grid systems. The goal of the QAF is to help ensure projects that are implemented have a higher likelihood of longterm sustainability, meeting the defined goals of the organizations implementing the projects. The steps outlined here are in many ways illustrative, but for the QAF to be successful in supporting the achievement of the overall project goals, it needs to be integrated with the development process.

\section{Step 1. Specify Project Goals}

Determine/define the parameters that will guide achieving the underlying goals of the electrification project, likely to include a minimum level of service, minimum system requirements, sustainability requirements, applicable electrical codes and standards, and other considerations. This process is likely conducted as part of a larger consultation process, balancing the program goals of key stakeholders. Key stakeholders: regulator, ministry, investors, and other organizations.

\section{Why This Is Important}

Clearly articulating the overall project goals is critical to enable objective evaluation while defining specific power-quality thresholds the specifying organization is expecting. Additionally, as part of the development process, the broad understanding of the overall project goals will help frame engagement on the program by potential participants.

\section{Relation to the QAF}

The QAF is implemented to provide two direct areas of focus: (1) it defines the minimum level of service (including power quality) that is accepted by the project stakeholders, and (2) it helps ensure that the identified goals of the project are met and can be documented.

\section{QAF Reference}

Section 2-Introduction to the Quality Assurance Framework, Section 3-Levels of Service Framework, and Section 4-Accountability and Performance Reporting Framework.

\section{Key Stakeholder Roles}

Regulator: Defines a set of minimal levels of service and other system conditions that meet national or international requirements, such as applicable construction codes, electrical codes, and equipment standards. If already existing, it may also identify a tariff structure or process through which one will be developed. Specifically, tasks are likely to include:

- Specify appropriate electrical standards for power system, transmission, distribution system, in-home wiring, and electrical supply

o Define a set of minimal levels of service, including power quality, power availability, and power reliability. 
Ministry: Typically oversees any large-scale rural electrification program, including the application of mini-grids. Defines the geographic area to be addressed, defines specific national goals for the project, and may specify any appropriate subsidy or governmental programs to support provision of power. Specific tasks are likely to include:

- Specify any power system or project requirements/criteria, such as the use of renewable energy technology

○ Define specific program/project metrics that should be tracked to document success

- As appropriate, define criteria by which individual projects will be selected.

Investors: Define terms of financing, including payback period and metrics for project sustainability. Goals may also define some additional requirements, such as a minimal level of service, additional monetary accountability requirements, or social considerations (e.g., use of specific technologies, gender equity). Some specific activities could include:

- Specify specific terms regarding project loans, grants, or equity investment, including payback timelines and defined rates of return

- Define specific program/project metrics that should be tracked to document success from the investment perspective

- Specify other investment criteria

- Provide input on specific levels of service to be provided, if appropriate.

Other: Typical consumer-focused NGOs or support agencies will also take part the development of the goals of larger rural electrification programs to ensure broad community-focused project input is included. The focus of these groups will differ, but they often focus on the rights of consumers to be impacted by the proposed projects. Some additional activities could include:

- Provide recommendation on specific levels of service and payment terms for typical consumers

O Support the development of project evaluation criteria.

\section{Step 2. Develop Policy and Ownership Frameworks}

Based on the program goals and defined power system ownership structures, specific policies may need to be enacted to facilitate mini-grid development. Many different power system ownership models have successfully provided energy services, from national monopoly utilities to community-based cooperative energy providers. Implementing a successful rural electrification program requires making a decision about what types of ownership models are going to be allowed for isolated mini-grid systems and then enacting policy to facilitate that choice. For example, in countries with a single utility, specific policy may be needed to allow independent power providers to provide electricity services to isolated customers. Other policies that will likely be required would define the terms of the power provision concession. ${ }^{5}$ For

\footnotetext{
${ }^{5}$ In the implementation of a rural electrification program, a power provision concession simply states that the responsible government organization is allowing a private or public entity to provide energy services to that community under specific terms. In order for private sector investors to provide funding to support the provision of energy services, some guarantees are required to help ensure they will be able to obtain a return on the investment.
} 
example, if a national grid comes to a community already being serviced by an independent power provider, it is important to know the terms under which concessions can be sold or combined, and under which terms power system concessions could be rescinded. If the legal framework allowing the deployment of isolated power systems is already in place, this step has already been completed. Key stakeholders: regulator, ministry, other.

\section{Why This Is Important}

Clear ownership models and the legal framework to allow those ownership models to provide energy services to customers are critical to the success of any rural electrification project. One of the primary reasons many mini-grid systems being installed currently fail is that the ownership structures and policy framework have not been put in place to ensure successful long-term operation. Additionally, when there has been enough growth where the ownership models and provider terms need to change, having policy in place guiding or regulating those transitions will help to eliminate lawsuits and other forms of resistance.

\section{Relation to the QAF}

The specific relationship to the QAF is limited, except that it assumes a defined entity has the role of the mini-utility, the organization that will be responsible for the long-term operation and maintenance of the resulting power system(s).

\section{QAF Reference}

Not applicable (N/A).

\section{Key Stakeholder Roles}

Eegulator: May or may not have a role in defining appropriate mini-grid ownership models, but, based on any policies enacted, may be required to define the process through which entities are approved to provide energy services. As an example, a policy may allow an independent power provider to provide energy services. In such a case, the regulator will need to determine what constitutes an independent power provider and what formalities or licensure, if any, are required for an organization to be named as one.

Ministry: Typically would work with the appropriate policy-making body to draft and implement specific policies to define the conditions through which specific organizations could provide power to isolated communities.

Other: Multiple stakeholders, NGOs that will likely play a role in the development and implementation of any energy-related policies. These stakeholders could include industry representatives, consumer representatives, universities, and other organizations such as multilateral donor organizations providing technical assistance in the development and implementation of alternative energy supply mechanisms.

\section{Step 3. Develop Reporting and Measurement Requirements}

Based on the project goals, determine what information must be collected to support/document the achievement of these goals. This could include several levels of data collection to address different goals. In addition to the specific parameters, frequency of measurements should also be

This concession can be allied to different ownership models, including the case where a national utility will own and operate all isolated mini-grid power systems. 
defined. The actual collection of this data is discussed later in this document. Key stakeholders: regulator, ministry, developers, mini-utility, investors, other.

\section{Why This Is Important}

In order to document whether or not the program and/or projects are proving successful, key parameters must be identified to allow tracking back to the original program goals. Different goals (expanded electrification, improved living conditions, project sustainability, productive use development, etc.) will require different measurement processes, which must be understood and documented early. Data collection and processing can be expensive; care should be taken to balance the need for data, the size of the projects, the burden of data collection, and the impact of successful collection and use. This data should also serve to inform decision-making stakeholders of evolving goals as progress is made in reaching initial programmatic goals and the electrification landscape changes.

\section{Relation to the QAF}

The QAF is defined around the concept of "truth in advertising," with each key stakeholder understanding the goals of the others and being able to document the process of meeting those goals. The QAF identifies a wide array of potential information that should be reported to document meeting identified goals, the selection of which will drive the level of measurement that should be undertaken. Measurement requirements should be tied directly to the documentation of project goals and the provision of safe electric service. They should not be completed for the sake of the measurements themselves.

\section{QAF Reference}

Section 4-Accountability and Performance Reporting Framework.

\section{Key Stakeholder Roles}

Regulator: Defines a set of parameters that the regulator feels will help ensure the defined levels of service are being met. This could include standards for consumers and the utility, likely focused on topics such as power quality, availability, and reliability. In some cases, project financial information will be collected to verify an appropriate tariff, although this information can also be required only when a tariff change is required. Specific tasks are likely to include finalizing the list of parameters and collection frequency to allow monitoring of specific regulatory and reporting requirements (levels of service).

IIIIII Ministry: Typically coordinates activities and specifies any information needed to understand how the project will achieve defined national goals. Specific activities could include:

- Finalize the list of parameters and frequency of collection to allow monitoring of specific programmatic considerations (number of connections, levels of service, etc.)

○ Coordinate collection of full data requests, primarily regulatory and financial.

Developers: Although not likely directly engaged in the process of defining specific data 具 $\frac{11}{3}$ collection needs, consultation with the development community will be needed to 
balance the burden of monitoring programs with practicality and cost. Local organizations engaged in the mini-grid market should be engaged in providing technical assistance to help prioritize data collection needs while integrating a better understanding of the data collection and reporting challenges.

Mini-utility: Although not likely directly engaged in the process of defining specific data collection needs from a regulation perspective, the utility will be responsible for the operation and maintenance of the mini-grid over the long term, will likely have the most inherent need for the data being collected, and will likely define additional information it would like collected. The utility will likely carry the burden for data collection and reporting. Local organizations working in the mini-grid market should be engaged in the development of monitoring requirements. The utility will also likely provide technical assistance to help prioritize data collection needs while integrating a better understanding of the data collection and reporting challenges.

Investors: Identify specific aggregate information needed to monitor investment quality based on the identified goals of the institution. Project investors will likely finalize a list of parameters and collection frequencies to allow monitoring of specific financial reporting needs.

Other: Consumer-focused NGOs or support agencies may be involved in the development of reporting requirements to ensure consumer and other interests are being met.

\section{Step 4. Develop Performance, Measurement, and Reporting Plans/Procedures}

Based on the identified reporting requirements, specify reporting documents, methodologies, and formats (data systems/equipment, reporting frameworks) to be included in the power system specification. This would also include the specification of approved measurement systems and the development of a process through which the project developers and utilities will provide identified data to specific parties. Note that the collection and storage of this data is addressed in Step 9, Collect and Analyze Long-Term System Operational Data. Key stakeholders: regulator, ministry, mini-utility, investors, other.

\section{Why This Is Important}

Based on the type of data to be collected, a process and the mechanisms needed to facilitate the data collection need to be developed. This would include how data will be collected and through what means. The development of an efficient data reporting structure also allows for specific information to be shared among partnering organizations, as well as the whole community.

\section{Relation to the QAF}

The structure of the accountability framework is driven by the collection of project information and data, which will allow all of the identified stakeholders to obtain a clear understanding of the projects from a performance and sustainability perspective. In addition to obtaining operational information from a single project, collecting similar data across multiple projects will allow for better understanding of programmatic success factors and areas in need of revision, and will eventually lower the overall risks of further project development. 


\section{QAF Reference}

Section 2-Introduction to the Quality Assurance Framework, Section 4-Accountability and Performance Reporting Framework, Appendix C: Sample Customer Disturbance Reporting Form, Appendix D: Sample Technical Reporting Form, and Appendix E: Sample Business Reporting Form.

\section{Key Stakeholder Roles}

Regulator: As the organization generally responsible for enforcing the proper operation of the power system(s), the defined regulatory organization will need to maintain information not only on the specifics of each project, but also on whether the projects are operating within the confines defined by the program goals and applicable system standards. The regulatory body would also likely monitor and ensure the quality of the data collection, while also hosting any data retention. Conceptually, data retention could be as simple as annual reports provided by the mini-utility or as complex as detailed time series data on power system operation. The ability of the regulatory authority to maintain such records would need to be considered prior to specification. It could be that the regulator will work with outside entities, as appropriate, to ensure any data suitable for wider distribution is made available. Other potential actions could include:

- Work with ministry to develop project data portals or information collection protocols where project data will be entered, collated, and stored

○ Work with the ministry, private sector developers, and/or operators (i.e., the miniutility) to specify appropriate data collection equipment for the program to achieve a level of reporting uniformity.

Ministry: Typically coordinates activities and is responsible for the overall development of the monitoring framework. The ministry could also be responsible for the development of the measurement procedures, including software and hardware needed to collect minigrid power system data. May lead or support the development and implementation of the project-level monitoring infrastructure that will be used to collect and analyze information received from individual projects, including the specification of appropriate data collection equipment. Once developed, these systems may be maintained by the ministry or transferred to other organizations, such as the regulator. The ministry may also document reporting requirements and approved monitoring approaches/equipment.

Mini-utility: May support the development or review of proposed guidelines. The utility is likely to provide technical assistance to help prioritize data collection processes while integrating a better understanding of the data collection and reporting challenges. The utility may play a larger role in performance data collection and reporting in instances where the project is being implemented by a private organization largely outside of government oversight. The mini-utility may also maintain long-term storage of system performance data if this is not completed by the regulatory agency.

Investors: Project/program investors have additional responsibility to ensure the terms of the funding provision are being met based on the goals identified for the project. This may overlap with the informational needs of the regulator or may be conducted independently of that effort. 
Other: Although not directly related to specific projects, the collection of long-term performance information from different mini-grid power systems will have larger technical and market-directed industry benefits. Outside scientific, research, or academic organizations may be in a position to collect, analyze, and store long-term performance data for projects. If this is the case, these organizations should likely take part in the specification of data collection parameters. In support of such larger data collection or system documentation efforts, an independent third party, such as an international donor organization, may become interested in contributing to the development of advanced data management protocols or systems. Given that many of the more useful elements of advanced data analysis will be universally applicable, the development of these tools by organizations not specific to a project may have broad applicability.

\section{Step 5. Develop a Project or Program Quality Assurance Verification Process}

Based on the reporting requirements and the program and/or project goals, a process of how to verify that the goals are being achieved will need to be developed. This process may involve many steps, including technology verification, data collection, independent accounting, and external review of critical project steps. The verification process initially focuses on the major terms of the project development, so that the power systems are built to the standards identified by the project goals, and over the long term the verification process ensures that the customers are receiving the agreed-upon level of service and/or that project sustainability goals are being met. This step would also include the development of the appropriate documents, such as the system commissioning protocol ${ }^{6}$ that will be needed to implement the verification process. This plan will provide a framework so all project partners understand the requirements that will be implemented as the project/program is launched. Key stakeholders: regulator, ministry, miniutility, investors.

\section{Why This Is Important}

The collection of project information is only as valuable as the confidence that the information is accurate. Since information is needed to determine whether the short- or long-term project goals are being met, a level of independent verification will be required to provide confidence in any reporting of goals. Additionally, before a specific power system should be accepted from a contractor, a defined set of predetermined tests or requirements should be met.

\section{Relation to the QAF}

The QAF is built on the premise that the access to information by the appropriate stakeholders will allow the mini-grid industry to develop in a way that more closely aligns with the modern utility sector, thereby reducing the risks currently associated with mini-grid systems, promoting increased learning about energy needs, and enabling replication of successful energy systems and

\footnotetext{
${ }^{6}$ A system commissioning protocol is a series of conditions and/or tests that should be undertaken as part of the acceptance of a new power system. The protocol would include checks for system safety equipment, that components meet the standards identified in the project plans, and that the system is providing the defined level of service to customers. The successful completion of the protocol signifies that the power system meets the design specifications and is considered ready to be placed into service. The completion of this process is typically a condition of payment for the company that is installing the power system. The development of such a plan allows the project installers to clearly understand what will be considered an acceptable final product and protects the program-implementing organization for taking ownership of below quality systems.
} 
business models. Successfully achieving this will lead to expanding access to private markets for both project development and broader market innovation. These outcomes become possible when the verification process establishes that the information is accurate.

\section{QAF Reference}

Section 2-Introduction to the Quality Assurance Framework and Section 4-Accountability and Performance Reporting Framework.

\section{Key Stakeholder Roles}

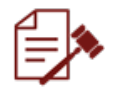

Regulator: Supports or leads the development and documentation of project verification plan that ensures proper system implementation and sufficient usefulness, quality, and reliability of the information being collected over the long term.

Ministry: Supports or leads the development and documentation of a project verification plan that ensures proper system implementation while also ensuring that the information being collected over the long term is of sufficient quality and reliability and aligns with long-term programmatic goals.

Mini-utility: May support the development or review of proposed guidelines, as its minigrid systems will be directly impacted by installed equipment. The mini-utility needs to be able to trust that the verified commissioning document assures successful integration of the commissioned equipment on the mini-grid.

Investors: Independent of the regulator, project investors may have requirements intended to ensure their investment performs as intended.

\section{Step 6. Develop Project Implementation/Requirements Guide/Document for Project Participants}

Implementing an energy program, more specifically when considering a larger multi-power community/system program, requires developing a program overview document/development guide that details all of the pertinent information for the projects. These documents are common for most development projects but typically do not include many of the elements that will help ensure long-term sustainability, especially for mini-grid projects. This program document would include many things, but in terms of the QAF it would define project goals, minimal levels of service, and the project monitoring and verification requirements. This document will likely be one of the core documents of the bid process so that potential project bidders/proposals have a common understanding of the system performance and reporting requirements. The primary stakeholder will lead the development of the project documentation in consultation with the other domestic and, in some cases, international stakeholders. Key stakeholders: regulator, ministry, investors, other.

\section{Why This Is Important}

To bid on the development of electrification projects that include the QAF principles, companies need to understand the specific requirements they will be held to. In locations where no formal bidding process is being used, this document informs organizations of what is expected of them when providing energy services. 


\section{Relation to the QAF}

This document would outline exactly how the QAF will be implemented on a project-by-project basis.

\section{QAF Reference}

Section 2-Introduction to the Quality Assurance Framework and Section 4-Accountability and Performance Reporting Framework.

\section{Key Stakeholder Roles}

Regulator: Develops or supports the development of project/program documentation that helps guide initial regulatory framework with recommendations for regulatory adjustment as mini-grids grow and larger-scale integration develops.

Ministry: Develops or supports the development of project/program documentation framing the parameters that guide the other stakeholders toward achieving the broader rural electrification goals.

Investors: Consultative engagement is expected.

Other: NGOs may take part in the development and/or review of project documentation, supporting the appropriate point organization in ensuring that the interests of additional stakeholders are incorporated into the development and implementation of the projects.

\section{Step 7. Implement Quality Assurance Verification Process}

Once implementation of the larger program or specific projects begins, the quality assurance verification process identified previously (Step 5) will need to be implemented. This step is distinct from the development of the quality assurance verification process, since different organizations will likely take part in this process. The implementation of this process will also require long-term oversight, training of verification personnel, and the provision of funding to support the long-term implementation of this plan. This will also likely include some methods to engage directly with project customers, potentially through independent, technology-based interviews, to ensure their needs are being addressed by the energy provider (mini-utility or developer). Some of this work could be implemented through private or public third-party entities. Key stakeholders: regulator, ministry, investors.

\section{Why This Is Important}

The only way to ensure the quality of the information that makes up a quality assurance process is through a defined verification process. If a verification process is defined but the standard checks and balances of the process are not implemented, the verification process will deteriorate over time, casting all of the program results into doubt. Over the long term, the only way the implementation of mini-grid projects as part of a large rural electrification program will be successful is if private funders have confidence that there is verifiable quality assurance information reflecting acceptable risk levels of the project/program.

\section{Relation to the QAF}

The QAF is built on the premise that the access to information for the appropriate stakeholders will allow the mini-grid industry to develop in a way that more closely aligns with the modern utility sector. 


\section{QAF Reference}

Section 2-Introduction to the Quality Assurance Framework and Section 4-Accountability and Performance Reporting Framework.

\section{Key Stakeholder Roles}

Ex. Regulator: Likely the primary organization responsible for establishing and overseeing the verification process. This process should be similar to other procedures the organization is implementing to regulate other elements of the energy sector. Since verification efforts may take different forms, such as on site field assessments, the implementation of automated data collection equipment, or the analysis of material submitted by project operators, specific training of regulatory staff or identified subcontractors is likely to be required.

Ministry: Supports implementation of the verification process, including participation in initial system commissioning activities.

Investors: May require/desire an independent, third-party verification effort to ensure and continually assess the risk of their investments.

\section{Step 8. Implement the Electrification/Mini-Grid Deployment Project/Program}

Although Step 8 is not specifically related to the QAF, this is the point at which the actual implementation of the rural electrification project/program could begin. The deployment project/program can be led by the ministry or organization with the overall responsibility for implementing rural energy activities at the government level or the private/public organization responsible for implementing the activities. The steps associated with this action are provided in Section 3, Implementation of the QAF on a Specific Power System, which provides guidance on how the QAF may be implemented on a project-by-project basis.

\section{Step 9. Collect and Analyze Long-Term System Operational Data}

The primary driver of long-term data collection and analysis is to provide a data-based framework for tracing progress toward project goals while providing information that would allow the modification of project conditions if the goals were not being met. This step consists of monitoring specific project data (performance, economic) and providing that data to key stakeholders and the wider mini-grid industry on an ongoing basis. This data helps ensure ongoing operational success and longer-term project sustainability while providing a mechanism for the key stakeholders to understand the progress being made toward programmatic goals. Concurrently, the collected data will help the mini-grid industry improve and become more efficient. Key stakeholders: regulator, mini-utility, investors, customers, other.

\section{Why This Is Important}

There are two main reasons this is important. Initially, relating to the operation of specific projects, ongoing data reporting allows a communal understanding of the progress toward project goals while providing information that would allow the modification of project conditions if the goals were not being met. The other reason to collect ongoing project data is to ensure the longterm sustainability of individual projects and rural energy programs in general; information being provided by these systems should be put to expanded use. The communal reporting of operational data from many projects provides three overriding benefits: (1) reduces the risk 
associated with the lack of long-term information about mini-grid projects, (2) fosters communal learning about energy use while documenting gains in rural energy access, and (3) provides data for the improvement of the technology and business approaches through refinement of the business models, optimization of power system operations, and more exact planning in relation to future energy needs. Automated collection also enables the generation of automated performance reporting and the notification of utility operators, regulators, and investors of operational issues.

\section{Relation to the QAF}

The QAF is built on the premise that access to information for the appropriate stakeholders will allow the mini-grid industry to develop in a way that more closely aligns with the modern utility sector, while providing enough data to inform realignment of specific goals if deemed necessary as electrification progresses. The ongoing collection, processing, and use of this data is one of the critical steps to enabling the successful implementation of this option to provide modern, low-cost energy services to communities that do not have such access presently.

\section{QAF Reference}

Section 4-Accountability and Performance Reporting Framework.

\section{Key Stakeholder Roles}

Regulator: Likely responsible for ensuring that data from specific projects are integrated into the information collection process defined for the project or program. Depending on the technical capabilities of this organization, actual data collection, analysis, and storage may be conducted by outside organizations, which is discussed below. This organization may be responsible for the development of mechanisms for outside organizations to make use of the data. If the project is being implemented by a private organization, the role of the regulatory body may be limited.

Mini-utility: The energy provider will likely be responsible for any manual data reporting and the maintenance of the reporting equipment. As one of the key sources and users of any system-specific data, the utility may develop additional automated reporting and alerting functionality as needed. The data may also inform decisions on necessary changes to operational protocols as mini-grids expand in size or become interconnected on a larger scale.

Investors: Project investors may require/desire specific access to project data, most specifically information that will support a better understanding of the project financial risks and the successful implementation of long-term project goals.

Customers: Customers need to be able to assess the level of service, as compared to expectations, and contracted service, as this directly impacts their willingness to pay for that service. Customers also must have a process to document the actual level of service provided and alert the appropriate stakeholders if they believe the appropriate service is not being provided.

Other: In support of any larger data collection or system documentation efforts, an independent third party, such as international donor organization, may become interested in supporting the development of advanced data management protocols or systems. Given 
that many of the more useful elements of advanced data analysis will be universally applicable, the development of these tools by organizations not specific to a project may have broad applicability. 


\section{Implementation of the QAF on a Specific Power System}

This section provides a step-by-step process that focuses specifically on Step 8, the implementation of specific power systems, either individually or as part of a larger, multisystem electrification program. It should be noted that there are typically two ways the development of a new process is handled. The first approach is a design, build, operate model where the program implementers support the identification of one entity to electrify a community. With the appropriate regulatory oversight and likely the implementation of specific stage gates, the project developer will conduct the full development process from community assessment through power system operation. The second approach relies on open market competition among companies that can provide specific services, such as the community needs assessment, power system design, system construction, and operational service. This helps ensure that there is no benefit to padding or inflating the project design parameters or costs, since the organization that is the recipient of the next step of the process is likely different. This second process does suffer from inefficiencies over the transfer of responsibilities and opens the project up to increased liability, since it can be hard to identify the cause of a specific error resulting in poor operation of the final product.

\section{Step 8A. Conduct Community Needs Assessments}

Needs assessments would be used to classify each of the potential users of new power systems using defined levels of service. This would be combined into a community load projection, potentially incorporating information on load growth taken from other local communities, and an assessment of the financial resources of the community. This information is then used to support the development of a power system design, proposed tariff structures, and any subsidy that may be required to balance the level of service expectations of the community and their ability to pay for that service. Key stakeholders: ministry, developers, investors, customers, other.

\section{Why This Is Important}

To develop a design for a mini-grid power system, an assessment of the community's energy needs is required. This should include current energy usage (typically without current energy services), expected near-term energy use (once energy is provided), and likely energy use over the next 3 to 5 years. Data collection should also include information on the willingness and ability to pay for electric service and cover all potential customers. As appropriate, collecting data on the specific locations of customers using global positioning technology will support the design of the power generation and distribution system design.

\section{Relation to the QAF}

Using the levels of service as defined within the QAF will allow information to be easily transferred between project stakeholders and/or across communities. Given that a minimum level of service is provided, understanding how many customers of different levels of service there are allows project designers to use a standard way of assessing specific energy needs, which allows learning from one project to be applied to others. A consistent assessment methodology that can be tracked over time allows better forecasting of energy needs for new and existing power systems. 


\section{QAF Reference}

Section 2-Introduction to the Quality Assurance Framework and Section 3-Levels of Service Framework.

\section{Key Stakeholder Roles:}

IIIIII Ministry: Define the process, forms, and/or criteria to be used in conducting energy assessments so the assessments can be compared across proposed projects. Some level of reporting of the results of the assessments should be included as part of the project development process.

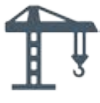

Developers: Likely responsible for conducting the assessments and tabulating specific community data. Since they will likely have gained on-the-ground experience through these assessments, they should be encouraged to provide any improved thinking on the overall development plan that may enhance the overall implementation processes.

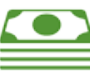

Investors: Depending on the overall goals of the project, project investors may require additional information to be collected as part of the community energy surveys. Potential additional information that will be used in the justification of project objectives includes answers to questions relating to potential productive uses, disposable income, and the health impacts of current energy options.

Customers: Potential consumers are involved through the provision of information regarding energy needs and their ability to pay for different levels of service.

Other: Although most tasks will fall to the project developers, local and regional NGOs may take part in community surveys, either in support of one of the organizations identified or independently. Their role would be to support the energy assessments as well as provide additional education services to community members on current or future energy practices, energy efficiency, and energy safety.

\section{Step 8B. Design Power System}

Using the design requirements, community loads assessment, resource information, and other data, a power system is designed for the community. This activity would typically fall outside of the specific engagement of the QAF but may have some verification requirements as defined in the quality assurance verification process (reviewing legal documents, providing construction oversight, system documentation, etc.). Because the projected cost of the power system will directly impact overall power costs, this process may be iterative with the development of the tariff structure (Step 8D below) to balance system costs, desired level of service, and community ability to pay. Key stakeholders: ministry, mini-utility, developers.

\section{Why This Is Important}

The appropriate design of a power system is one of the long-term drivers of project success.

\section{Relation to the QAF}

The specific relation to the QAF is limited, although specific project goals by the investor, such as a potential reliance on a specific power generation technology, will drive system design and subsequent reporting requirements. 


\section{QAF Reference}

Section 2-Introduction to the Quality Assurance Framework.

\section{Key Stakeholder Roles}

Ministry: Assuming the ministry is the organization leading the project, it is likely the entity that provides a quality control check and then approves the final system design.

Mini-utility: As the entity responsible for the long-term operation and maintenance of the mini-grids and eventual larger integration of mini-grids, the utility should be fully informed of power system designs, especially as they may evolve over time, becoming larger in size individually and in aggregate.

Developers: Building off the data collected during the community assessment and the requirements specified in the project implementation/requirements guide/document (Step 6 above), developers will develop a power system design.

\section{Step 8C. Complete Project Permitting}

Some level of development permitting will often be required in the development and deployment of any power system. Permitting efforts may be required specifically in relation to the provision of power, such as a generation license agreement; specific components of the power system, such as the installation of wind turbine towers; or to address other potential development impacts, such as environmental impacts. The level of permitting requirements will likely be dependent on the governing jurisdiction and financing organization. Key stakeholders: regulator, ministry, developers, customers, other.

\section{Why This Is Important}

Some form of permitting or licensing is often required, specifically around the development of energy systems. Expanding beyond simple safety guidelines, the need to understand and document the potential impact of energy system development is a common governmental concern. Developing the right balance of permitting is also quite important to project development. Limited permitting can result in the development of projects in a very haphazard manner such that governmental organizations do not know where projects are being developed. Permitting that is too strict can limit development due to greatly increased project timelines and higher development costs.

\section{Relation to the QAF}

The specific relation to the QAF is limited, although some elements of the accountability framework could be included in specific regulatory or permitting requirements.

\section{QAF Reference}

Section 2-Introduction to the Quality Assurance Framework.

\section{Key Stakeholder Roles}

Regulator: Likely responsible for defining the regulatory process and collecting specific information as set forth in policy around the development of mini-grid power systems, including what information must be submitted by power providers as part of the 
development process. In some cases, different regulatory organizations will be responsible for different permitting requirements.

Ministry: May define overall requirements for the development of mini-grid power systems, including the general level and type of permitting requirements. In some cases, different ministries will be responsible for the specification of different permitting requirements.

Developers: Typically responsible for understanding and insuring the compliance with all required permitting requirements.

Customers: In some jurisdictions, consumers or local community members may have a large role in the permitting processes, specifically around local requirements for land development, environmental impact, or the provision of power services. In most cases, early engagement with community members is valuable to ensure that local permitting goes smoothly. Although it is likely to help, the simple provision of energy services to a community does not typically mean community members will all be in favor of the project.

Other: In many instances, nongovernmental bodies play an active role in the permitting processes, most specifically around the environmental impact of project development. Engaging with local stakeholder groups impacted by the project and ensuring that the impacts of the project are fully understood and documented will greatly facilitate smooth project development.

\section{Step 8D. Determine Rate Structure}

To balance the ability/willingness to pay for energy services with providing the level of service needed/desired while maintaining project sustainability, an acceptable tariff must be defined for the power being sold. This is a challenging, likely iterative process that requires balancing the total project costs and the ability to support those costs through power sales, subsidies, or other means. Additional factors, such as opportunities to reduce or lower project costs (incentives, grants, low-cost financing, and flexibility in power quality), as well as support for power sales (energy subsidies, anchor clients, governmental sector power consumers, expansion of the mix of residential and commercial consumers), will impact this assessment. This calculation will drive current and future production requirements in that power costs are correlated to consumption and power system design (size and power quality). The actual methods to collect payment, such as through the use of prepay meters, should be determined at this stage of project development. Consequences of nonpayment should also be determined ahead of time, as the impacts of nonpayment will likely have a negative impact on the confidence level of the investor. Key stakeholders: regulator, ministry, mini-utility, investors, customers, other.

\section{Why This Is Important}

Long-term project sustainability requires that the revenues generated by the project can cover the identified costs (development, construction, operation, maintenance, and appropriate profit) while continuing to meet the energy needs of the customers. Understanding the difference between consumers' ability and willingness to pay as related to total project costs enables the identification of needed governmental investment. 


\section{Relation to the QAF}

The specific relation to the QAF is limited, except that, as appropriate, different rates should be applied to different levels of service.

\section{QAF Reference}

Section 2-Introduction to the Quality Assurance Framework.

\section{Key Stakeholder Roles}

Regulator: Likely the entity that approves electric rates by level of service for a specific project or rural electrification program.

Ministry: To ensure long-term project sustainability, the revenue from the project must cover the costs of that project, plus any expected profit, and also fulfill the regulatory requirements of affordable, reliable power. In some instances, the government may provide funding to support individual projects to assure financial viability and reach larger rural electrification goals. This support would lower the total life-cycle cost of power to the consumer, matching their willingness and ability to pay. Subsidies can be implemented in many ways, including but not limited to covering a portion of the initial project cost or providing a subsidy to reduce the base electric rates for specific user classes.

Mini-utility: Building off the power system designs, the mini-utility or energy provider (in some cases the developer) will provide information on the expected cost of power provision incorporating capital and operational costs. Determine consumer payment methods in collaboration with appropriate project partners.

Investors: Project investors must receive a risk-adjusted rate of return for their investment and so have a vested interest in participating in the development of an appropriate tariff structure for power systems they are financing.

Customers: Specific customers are typically not engaged directly in the tariff setting process; however, they are clearly a key stakeholder group with a vested interest in the result.

Other: In place of specific customers, consumer groups typically take part in the discussion around the setting of new tariffs. Their involvement may or may not be required, but they should be engaged if possible.

\section{Step 8E. Install Power System}

The installation of the power system is typically outside of the specific engagement of the QAF but should have some verification requirements as defined in the quality assurance verification process (reviewing legal documents, providing construction oversight, system documentation, etc.) and is usually handled between the project developer and governmental organization (regulatory or ministerial) leading the electrification program. Key stakeholders: regulator, developers.

\section{Why This Is Important}

The commissioning process (Step 8G below) will address any specific performance requirements; for larger power systems standard project construction due diligence will be 
warranted throughout the power system construction project. The effort will ensure the use of proper materials and construction practices, leading to a power system that is more likely to perform adequately over the planned life of the project.

\section{Relation to the QAF}

The specific relation to the QAF is limited, except that specific design requirements, construction standards, and construction verification protocols should be identified in the development of the project requirements guide.

\section{QAF Reference}

Section 2-Introduction to the Quality Assurance Framework.

\section{Key Stakeholder Roles}

Regulator: Specification of design standards for construction, including required construction documentation.

Developers: Install the power system and complete project documentation.

\section{Step 8F. Implement Power Monitoring System}

As defined in the project verification process, if integrated and/or independent power system or load monitoring is specified, this will be implemented once the power system is installed or during the final stages of the implementation process. Such a monitoring system could include advanced condition monitoring to allow active system management (such as predictive maintenance, estimated near- and long-term energy needs, and fault detection) or be relatively simple in nature, ensuring there are easy access points to make energy measurements using hand measurement equipment at locations such as a customer electrical drop. The project validation documentation should specify whether this is to be implemented by an independent third party or can be integrated into the power system operations and control. Key stakeholders: regulator, ministry, developers, mini-utility, investors.

\section{Why This Is Important}

Collecting accurate operational information on a project will be required to ensure an understanding of long-term operational trends, improve system efficiency, understand market growth, document that the project is successfully providing the level of service defined under the project goals, and provide a source for the information that will be required to further develop the overall off-gird energy market.

Relation to the QAF

Monitoring is critical to the implementation of the QAF.

\section{QAF Reference}

Section 2-Introduction to the Quality Assurance Framework. 


\section{Key Stakeholder Roles}

Regulator: Leads or supports the integration and validation of the specific power system monitoring into the larger project monitoring infrastructure. If automated monitoring is being implemented, integrates the project monitoring system into the program monitoring framework.

Ministry: Will likely coordinate the integration and validation of the monitoring package with the appropriate regulator and, if automated monitoring is being implemented, integrate the project monitoring system into the program monitoring framework. If individual mini-grid monitoring systems are being implemented by an independent third party, the ministry may oversee or participate in the installation of the monitoring package.

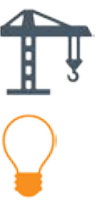

Developers: Install or support the installation and integration of the monitoring system.

Mini-utility: Installs or supports the installation and integration of the monitoring system. This information will help preemptively support grid expansion analyses over time.

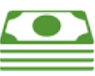

Investors: May require monitoring in addition to that completed to meet regulatory requirements; if so, this will also need to be implemented.

\section{Step 8G. Commissioning the Power System}

Before the power system should be accepted or interconnected to homes, a series of tests and reviews should be undertaken to ensure that it was constructed to meet specific safety and power quality requirements identified as part of the QAF verification process. The specifics of the power system commissioning should be detailed in the QAF verification plan and project documents. This may include third-party review of project construction documents and a series of functional tests to ensure proper operation. This becomes more critical if there is to be a transfer of ownership of any of the power system assets or if some form of payment is made to the designers or installers of the power system. If an independent power producer or design, build, operate model is being used, the depth of the power system commissioning can be reduced. The system commissioning usually takes place prior to a more ceremonial dedication. Key stakeholders: regulator, ministry, developers, mini-utility, investors.

\section{Why This Is Important}

The commissioning of a power system is a functional test of the operability of system, ensuring to the extent possible that the design requirements have been met. The commissioning typically also represents a legal milestone in which payments and/or the transfer of ownership of the power system is made. Even if no funds are being exchanged, such as in a no cash concession model, the program should still ensure that the level of service specified is being provided in a safe manner.

\section{Relation to the QAF}

Although not directly related to the QAF, the power system must demonstrate that it can provide the contracted level of service before power can be provided to the customers, with the expectation that those customers will pay for the service being provided. 
Section 2-Introduction to the Quality Assurance Framework.

Key Stakeholder Roles

$\square$ Regulator: The primary third party responsible for insuring that the power system and associated equipment, including the distribution infrastructure, has been installed to meet appropriate national or international standards and that the system is providing the defined level of service.

IIIIII Ministry: Primary party responsible for insuring that the contractual requirements for the development of the power system and associated hardware have been met. The overall program lead is likely responsible for taking ownership or transferring ownership of the power system and approving the payment for its construction.

Developers: Assume primary responsibility for administering the commissioning tests and demonstrating that the power system is meeting the defined requirements.

Mini-utility: Typically a participant and signatory to the commissioning process because the utility will take eventual ownership or operational responsibility of the power system and so has a vested interest in ensuring compliance. The utility should be fully informed of power system commissioning to ensure "as-built" matches "as-designed."

Investors: As the project funders, investors are typically represented at the project commissioning. 


\section{Conclusion}

According to the IEA, the deployment of mini-grids is essential for achieving universal energy access. However, uncertainty about the quality of service, accurate billing, low reliability, and safety increases transaction costs, making it difficult to attract low-cost financing and develop sustainable business models. These significant challenges hinder the scaling up of mini-grid deployment. The QAF seeks to address these challenges by defining a range of service levels that ensure safe, quality, and affordable delivery of basic grid-parity service, and by providing an accountability framework that can be used to determine whether an agreed-upon service level is delivered. This implementation guide, a companion document to the QAF, is intended to facilitate the deployment of the QAF.

Stakeholders involved in the mini-grid implementation process can be follow this guide on a step-by-step basis throughout the process or refer to it during individual steps. The guide is intended to be applied to both large-scale rural electrification programs spanning multiple minigrid systems and specific individual systems. Additionally, the guide can be used by multiple stakeholder groups that are typically involved in the mini-grid implementation process, including but not limited to the ones specifically identified in this document. 